\title{
CONTRATAÇÕES PÚBLICAS SUSTENTÁVEIS NO BRASIL: UMA OBRIGAÇÃO HISTÓRICA, CONSTITUCIONAL E LEGAL
}

\author{
Luciano Araújo de Castro* \\ Carlos Bastide Horbach**
}

SUMÁRIO: Introdução; 1 Necessidade de uso Sustentável dos Recursos Naturais e o Papel do Estado; 2 o Dever Constitucional de o Estado Brasileiro Defender e Proteger o Meio Ambiente; 3 As Contratações Públicas Sustentáveis como Imposição Constitucional; 4 As Contratações Públicas Sustentáveis como Imposição Legal; 5 Considerações Finais; Referências.

RESUMO: A aceleração do processo de degradação ambiental, verificado no pósguerra, evidenciou os limites do planeta em sustentar o modelo de crescimento vigente e ensejou a redefinição do papel do Estado para enfrentar os novos desafios, inclusive quanto ao seu próprio consumo, que deveria então ser sustentável. O objetivo deste artigo é demonstrar que, no Brasil, esse novo modelo de consumo, por mandamento constitucional e legal, deve ser praticado e fomentado pelo poder público por meio da realização de contratações públicas sustentáveis, de modo que não há margem discricionária para o gestor público buscar obter, como proposta mais vantajosa, senão um contrato que, ao mesmo tempo, congregue, em nível ótimo, preço, qualidade e sustentabilidade. A metodologia de trabalho consiste na exploração das possibilidades do texto constitucional sobre o tema, na leitura sistemática da legislação existente e no diálogo com a doutrina especializada.

PALAVRAS-CHAVE: Estado; Contratações Públicas; Sustentabilidade.

\section{SUSTAINABLE PUBLIC CONTRACT IN BRAZIL: A HISTORICAL, CONSTITUTIONAL AND LEGAL DUTY}

ABSTRACT: Acceleration in the process of environmental degradation especially in the wake of WWII evidenced the planet's limitations to sustain a growth model and demand a re-definition of the State's role to face challenges, included consumption which must be sustainable. Current essay demonstrates that the new consumption model in Brazil, triggered by constitutional and legal stance, should

\footnotetext{
"Mestrando no Programa de Mestrado em Direito Centro Universitário de Brasília - (UniCEUB), Brasília, DF, Brasil; E-mail: luciano3005@hotmail.com

${ }^{* *}$ Doutor em Direito do Estado pela Universidade de São Paulo (USP); Docente de Direito Constitucional da Faculdade de Direito da Universidade de São Paulo (USP); Docente do curso de Graduação e do Programa de Mestrado e Doutorado em Direito do Centro Universitário de Brasília - (UniCEUB), Brasília, DF, Brasil.
} 
be practiced and enhanced by authorities through sustainable public contracts. No discretional items should exist so that the public administration seeks to obtain, as the most advantageous proposal, a contract which also aggregates price, quality and sustainability at the best level. The paper comprises the exploitation of possibilities of the constitutional text on the theme, the systematic reading of legislation and dialogue with specialized doctrine.

KEY WORDS: State; Public Contract; Sustainability.

\section{CONTRATACIONES PÚBLICAS SOSTENIBLES EN BRASIL: UNA OBLIGACIÓN HISTÓRICA, CONSTITUCIONAL Y LEGAL}

RESUMEN: La aceleración del proceso de degradación ambiental, verificado en el post-guerra evidenció los límites del planeta en sostener el modelo de crecimiento vigente y llevó a la redefinición del papel del Estado para enfrentar los nuevos desafíos, incluso en lo que se refiere a su propio consumo que debería ser sostenible. El objetivo de este artículo es demostrar que, en Brasil, ese nuevo modelo de consumo, por mandamiento constitucional y legal, debe ser practicado y fomentado por el Poder Público, por medio de la realización de contrataciones sostenibles, de modo que no haya margen para el gestor público buscar obtener, como propuesta más ventajosa, el contracto que, al mismo tiempo, añada en buen nivel, precio, calidad y sostenibilidad. La metodología de trabajo consiste en la explotación de las posibilidades del texto constitucional sobre el tema, en la lectura sistemática de la legislación existente y en el dialogo con la doctrina especializada.

PALABRAS-CLAVE: Estado; Contrataciones Públicas, Sostenibilidad.

\section{INTRODUÇÃO}

Após a Segunda Guerra Mundial, com a implementação, nos países desenvolvidos, do Welfare State (ou a tentativa de sua implementação, nos países ditos emergentes), acelerou-se ainda mais um processo de degradação do meio ambiente, o qual, ao tempo em que sinalizou para os limites da exploração dos recursos do planeta, engendrou uma série de questionamentos sobre o modelo de crescimento vigente. Nesse contexto, disseminou-se - embora sem contornos de unanimidade - a percepção da necessidade de se utilizar racionalmente os recursos naturais disponíveis. 
No presente trabalho, discorrer-se-á sobre como esse panorama exigiu a redefinição do papel do Estado, inclusive relativamente a um novo paradigma de consumo que ele, Estado, ao tempo que o teve de adotar, viu-se, também, compelido a fomentar. Tentar-se-á demonstrar que, afora essa contingência histórica que igualmente o alcança, o Estado brasileiro também se encontra compelido a revisitar seu modelo de consumo em decorrência de comandos constitucionais e infraconstitucionais, devendo, por conseguinte, obrigatoriamente, promover contratações públicas sustentáveis.

Esclareça-se, desde logo, que a discussão acerca das dificuldades práticas que a inserção em definitivo da sustentabilidade acarreta no processamento das licitações e contratações públicas - matéria extensa e complexa, a reclamar, pois, enfretamento em estudo específico - não está inserida no escopo deste artigo que, insiste-se, circunscreve-se a debater as bases teóricas e normativas do dever estatal de realizar contratações públicas sustentáveis, bem como apontar algumas implicações desse debate.

\subsection{NECESSIDADE DE USO SUSTENTÁVEL DOS RECURSOS NATURAIS E O PAPEL DO ESTADO}

Jared Diamond ${ }^{3}$, em seu best seller "Colapso", conta a história de sociedades passadas que, logo após experimentarem seu auge, sofreram um súbito declínio em razão do uso inadvertido dos recursos naturais, praticando, assim, o que autor denominou de "ecocídio". Nesse bloco estão os rapanui, da ilha de Páscoa, os maias, das Américas Central e do Norte, os vikings, da Groelândia Nórdica, e os anasazis, da América do Norte.

Embora as sociedades que colapsaram apresentassem graus diversos de vulnerabilidade em virtude das condições naturais do território que ocupavam ou em razão da maior ou menor preponderância de outros fatores - mudanças climáticas não provocadas pelo homem, vizinhança hostil e parceiros comerciais mais ou menos amistosos -, em todas elas teria sido determinante para o declínio a utilização dos recursos naturais para além da capacidade suportada pelo meio ambiente circundante.

É inquietante a indagação, formulada pelo autor, de por que aquelas sociedades não conseguiram perceber, a tempo de remediá-la, a utilização excessiva

3 DIAMOND, Jared. Colapso: como as sociedades escolhem o fracasso ou o sucesso. 5 ed. Rio de Janeiro: Record, 2007. 
e inadequada dos recursos naturais que lhes garantia a sobrevivência e modo de vida, erros que, hoje, parecem tão óbvios ${ }^{4}$.

Atualmente se presencia uma utilização dos recursos naturais também para além do limite que, aparentemente, o planeta parece suportar, sendo diariamente noticiados indicadores nesse sentido: o aquecimento global, a elevação do nível dos oceanos, o aumento de áreas desérticas, a redução da biodiversidade, dentre outros. É inquietante pensar na possibilidade de haver uma utilização tão inadequada dos recursos disponíveis que venha a comprometer, em definitivo, num futuro próximo, o modo de vida e, no limite, a própria subsistência da espécie humana.

Retrocedendo-se um pouco às origens recentes desse cenário atual, o ritmo mais acelerado de degradação do meio ambiente pela ação antrópica é observado a partir da Revolução Industrial, quando a massificação da produção e do consumo de bens acarretou um avanço predatório sobre os recursos naturais do planeta até então nunca vistos. Desde então esse cenário apenas se intensificou, alcançando seu ápice no fordismo, modelo de crescimento econômico do pós-guerra, o qual, segundo Sérgio Buarque , "parecia solidamente implantando e inabalável, fundado sobre o tripé abundância de recursos naturais (e energéticos), aumento da produtividade do trabalho e presença do Estado de Bem Estar" (grifos do original).

No entanto a crença generalizada na capacidade material do planeta de sustentar eternamente esse modelo de crescimento passou a ser questionada, de forma mais consistente, a partir do final dos anos 1960, ante as evidências, cada vez mais frequentes, de que os recursos naturais são, na verdade, finitos. Simbólica nesse sentido foi a crise do petróleo do começo da década de 1970, após a qual o preço do produto experimentou uma rápida elevação, sinalizando para a limitação dos seus estoques.

Bastante ilustrativo dos questionamentos surgidos é o artigo de Kenneth Boulding ${ }^{6}$, de 1966, "The economics of the coming spaceship Earth". Nele, é traçado

\footnotetext{
${ }_{4}^{4}$ Nesse sentido, por exemplo, Jared Diamond relata que, segundo comprovam estudos científicos, durante os primeiros anos de colonização, Páscoa possuía uma floresta subtropical de grandes árvores. No entanto, embora fosse matéria-prima para a construção de canoas e para o transporte das conhecidas estátuas (os Moai), combustível para o frio e fonte de caça, toda essa floresta foi destruída pela ação dos seus habitantes, tanto que, quando o descobridor holandês Jacob Roggeveen chegou em 1722, não detectou qualquer vegetal com mais de 3 metros de altura. Com o fim das florestas foram-se as matérias-primas, a comida da caça e a fecundidade do solo (decorrente da erosão, ressecamento e perda dos nutrientes). A população de Páscoa, então, conheceu a fome, a guerra e o canibalismo, entrando em declínio. Quem teria tido a coragem de derrubar a última árvore? (Ibidem, 2007, p. 51-75.)

5 BUARQUE, Sérgio. Construindo o desenvolvimento local sustentável: metodologia de planejamento. 4 ed. Rio de Janeiro: Garamond, 2008. p. 15.

${ }^{6}$ BOULDING, Kenneth. The economics of the coming spaceship Earth, 1966. Disponível em: < http://www. ub.edu/prometheus21/articulos/obsprometheus/BOULDING.pdf>. Acesso em: 25 jul. 2015.
} 
um feliz paralelo entre a economia do caubói, modelo até então praticado pelo homem e que tinha por pressuposto a suposta capacidade infinita do planeta em prover os recursos necessários ao crescimento econômico, e a economia da espaçonave, antevista pelo autor, na qual a Terra do futuro era comparada a uma espaçonave em que, diante dos evidentes limites dos recursos disponíveis e da capacidade de absorção da poluição, seus ocupantes são obrigados, em nome da própria sobrevivência, a reorientar seu modo de vida.

Na mesma esteira, o estudo "Limites do Crescimento", de 1972, vigorosa pesquisa sobre o entrelaçamento entre o crescimento populacional, o modelo de crescimento industrial vigente e os limitados recursos naturais, concluiu, por meio do cruzamento de dados, realizado por um sistema de computador, que o padrão de consumo vivenciado ou desejado pelos países não era sustentável e que, se mantido, levaria, em poucos anos, ao colapso mundial. Conforme ponderou o Clube de Roma, patrocinador do estudo, diante das previsões trágicas decorrentes de uma ultrapassagem das fronteiras de resistência do meio ambiente mundial, o homem, a partir de então, via-se, forçadamente, "a levar em consideração as dimensões limitadas de seu planeta, e os limites de sua presença e de suas atividades".

Estando disseminada ${ }^{8}$ a condição de esgotáveis dos recursos naturais e, portanto, sua incapacidade de suportar o modelo de crescimento econômico até então levado a efeito pela maioria dos países, a Assembleia Geral das Nações Unidas, em 1983, cria a Comissão Mundial sobre Meio Ambiente e Desenvolvimento e a incumbe de elaborar "uma agenda global para mudança".

Essa comissão, em 1987, produziu um relatório que ficou conhecido como "Nosso Futuro Comum" ou "Relatório Brundtland" (em homenagem à presidente da comissão, então primeira-ministra da Noruega, Gro Harlem Brundtland). Nele, considerando que o "meio ambiente e desenvolvimento não constituem desafios separados", eis que "o desenvolvimento não se mantém se a base de recursos

\footnotetext{
MEADOWS, Donella et. al. Limites do crescimento: um relatório para o Projeto do Clube de Roma sobre o dilema da humanidade. 2 ed. São Paulo: Perspectiva, 1978. p. 186.

${ }^{8}$ Não se ignora que, ainda hoje, haja quem duvide da limitação do planeta em prover, indefinidamente, o padrão de consumo dos países ricos que, ao final e ao cabo, é perseguido pelos países emergentes e desejado pelas nações pobres. $\mathrm{E}$, de resto, ao que se percebe, no campo prático, ainda se está no começo do processo de transição da economia do caubói para a economia da espaçonave. Vide, por exemplo, a recalcitrância de dois dos maiores poluidores mundiais - China e EUA - em aderir a consensos internacionais para redução das emissões de carbono. O que se colocou em realce é que a concepção da existência de um limite para a exploração dos recursos naturais e, por conseguinte, do modelo de crescimento vigente já não consistiam, àquela altura, uma novidade, embora não se tratasse de uma concepção aceita à unanimidade.

9 BRUNDTLAND, Gro (Rel.). Nosso futuro comum. Comissão Mundial sobre Meio Ambiente e Desenvolvimento. 2 ed. Rio de Janeiro: Fundação Getúlio Vargas, 1991, p. 40-43.
} 
ambientais se deteriora", assim como "o meio ambiente não pode ser protegido se o crescimento não leva em conta as conseqüências da destruição ambiental”, propõese como estratégia para superação da crise ambiental o conceito de desenvolvimento sustentável.

Desenvolvimento sustentável, de acordo com o "Relatório Brundland"10, "é aquele que atende às necessidades do presente sem comprometer a possibilidade de as gerações futuras atenderem a suas próprias necessidades", alicerçando-se, para esse fim, no tripé crescimento econômico, justiça social e proteção ambiental ${ }^{11}$. Nota-se, pois, que não se negou o crescimento econômico, mas antes se propôs sua requalificação por meio da reorientação dos seus pressupostos (crescimento apenas se acompanhado de preservação ambiental) e objetivos (crescimento para todos).

Verificadas as origens recentes do cenário ambiental atual e a evolução dos questionamentos surgidos a respeito, tem-se que, havendo, como há, uma crise ambiental que ameaça, no limite, a própria sobrevivência da civilização contemporânea, a reclamar imperiosamente, por conseguinte, outro padrão de crescimento - o desenvolvimento sustentável -, é intuitivo que o papel do Estado precisa se redefinir para enfrentar esses novos desafios.

Com efeito, embora a questão ambiental, por sua dimensão planetária e complexidade social e técnica, requeira um esforço compartilhado entre os diversos atores sociais - o que, naturalmente, inclui o mercado e a sociedade -, é ao Estado que compete, primordialmente, a indução da necessária mudança de paradigma, seja no plano externo, na formulação de consensos com os demais países, seja no plano interno, em que detém o monopólio legislativo e a primazia na definição de políticas públicas.

No ponto, Sergio Buarque ${ }^{12}$ pondera que "as propostas contemporâneas de desenvolvimento - como o desenvolvimento sustentável - tendem a aumentar a importância e necessidade do planejamento como um instrumento fundamental para orientar o futuro". E esse planejamento há de ser prioritariamente estatal (embora não exclusivamente), eis que a atuação do Estado é indispensável onde "o mercado não é eficaz como regulador espontâneo da economia desde uma perspectiva

\footnotetext{
${ }^{10}$ Ibidem, 1991, p. 46.

${ }^{11}$ Posteriormente, o conceito de desenvolvimento sustentável sofrerá críticas por sua amplitude e ambiguidade e, também por isso, reformulações e aperfeiçoamentos que darão origem a divergências, mas, também, a uma maior densidade do conceito. Essas discussões, embora tão importantes, fogem do desiderato deste artigo e, por isso, não serão trabalhadas aqui. Fica, porém, o registro da controvérsia existente, a ser explorada em outro estudo, oportunamente.

${ }^{12}$ BUARQUE, Sérgio, op. cit., 2008, p. 23.
} 
de médio e longo prazos, precisamente nas dimensões social e ambiental, e nos segmentos estratégicos de limitada e lenta rentabilidade".

$\mathrm{O}$ autor ${ }^{13}$ justifica a necessidade de um planejamento estatal ao argumento de que a eficiência econômica do mercado restringe-se a um "horizonte temporal curto", sendo "estritamente econômico-empresarial". Assim, o mercado não seria capaz de trabalhar com componentes do novo paradigma de desenvolvimento que requerem horizontes temporais mais dilatados, a saber: conservação ambiental, equidade social e equilíbrio espacial. De modo que, nessa seara, não havendo a ação reguladora do Estado, "a dinâmica econômica tende a comprometer a sustentabilidade no longo prazo, porque costuma promover a degradação ambiental, a concentração dos benefícios sociais e a concentração espacial da riqueza".

Não parece exagerado afirmar, portanto, que a promoção do desenvolvimento sustentável pelo Estado reflete uma exigência histórica, da qual não lhe é conferido eximir-se; se o Estado foi e é fundamental para a organização da vida em sociedade, agora seu desafio é outro, maior e mais difícil, consistente em assegurar as condições de manutenção de vida humana digna na Terra.

Mas a atuação estatal em prol de um desenvolvimento sustentável não é, no caso do Brasil, apenas uma imposição de cunho histórico, embora definitivamente o seja. Com efeito, em face dos seus predicados todos superlativos - território, população, economia, biodiversidade -, a ausência de compromisso do país com a agenda ambiental mundial seria, por assim dizer, uma ausência sentida, por sua indiscutível relevância para o equilíbrio do ecossistema global. O que se sublinha é que, afora essa contingência histórica, o compromisso de o país adotar uma agenda ambiental constitui mandamento constitucional, conforme se passa a evidenciar.

\section{O DEVER CONSTITUCIONAL DE O ESTADO BRASILEIRO DEFENDER E PRO- TEGER O MEIO AMBIENTE}

José Afonso da Silva ${ }^{14}$ historia que a Carta de 1998 foi a primeira a tratar "deliberadamente da questão ambiental", eis que as constituições nacionais anteriores nada dispunham, diretamente, sobre o tema, embora se pudesse extrair "orientação protecionista do preceito sobre a competência da União para legislar

${ }^{14}$ SILVA, José Afonso da. Direito Ambiental Constitucional. 10 ed. São Paulo: Malheiros, 2013. p. 49. 
sobre água, florestas, caça e pesca, que possibilitavam a elaboração de leis protetoras como o Código Florestal [...]".

Frisa-se, por oportuno, que a proteção normativa do meio ambiente não se inicia, evidentemente, com a Constituição de 1988, eis que foram editadas leis com esse viés anteriormente, contudo, como observa Nicolao Dino ${ }^{15}$, não existiam "balizamentos mais aprofundados em nível constitucional, capazes de nortear objetivamente a normatização com vistas à proteção do meio ambiente como um todo".

Com efeito, a Constituição vigente instituiu um capítulo específico para versar sobre o meio ambiente (Capítulo VI, "DO MEIO AMBIENTE"), inserindo-o no Título VIII ("DA ORDEM SOCIAL"), embora disposições de cunho ambiental estejam espraiadas, de modo implícito ou explícito, em outras passagens do texto constitucional (assim, apenas a título ilustrativo, o art. $5^{\circ}$, XXIII, XXIV e LXXIII ${ }^{16}$, art. $23, \mathrm{VI}^{17}$, art. $129, \mathrm{III}^{18}$ e art. $170, \mathrm{VI}^{19}$ ). No conjunto, na avaliação de José Afonso da Silva $^{20}$, cuida-se de uma Carta "eminentemente ambientalista", tendo assumido "o tratamento da matéria em termos amplos e modernos".

A dimensão da proteção constitucional dispensada ao meio ambiente, consoante ponderam Heline Sivini Ferreira e José Rubens Morato Leite ${ }^{21}$, "tende a aproximar o país de um modelo estatal ecologicamente mais orientado", ou seja,

\footnotetext{
${ }^{15}$ DINO, Nicolao. Proteção jurídica do meio ambiente. Belo Horizonte: Del Rey, 2003. p. 120.

${ }^{16}$ Art. $5^{\circ}$ Todos são iguais perante a lei, sem distinção de qualquer natureza, garantindo-se aos brasileiros e aos estrangeiros residentes no País a inviolabilidade do direito à vida, à liberdade, à igualdade, à segurança e à propriedade, nos termos seguintes:

XXIII - a propriedade atenderá a sua função social;

${ }^{x} X I V$ - a lei estabelecerá o procedimento para desapropriação por necessidade ou utilidade pública, ou por interesse social, mediante justa e prévia indenização em dinheiro, ressalvados os casos previstos nesta Constituição;

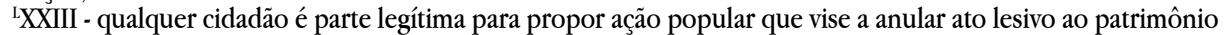
público ou de entidade de que o Estado participe, à moralidade administrativa, ao meio ambiente e ao patrimônio histórico e cultural, ficando o autor, salvo comprovada má-fé, isento de custas judiciais e do ônus da sucumbência;

${ }^{17}$ Art. 23. É competência comum da União, dos Estados, do Distrito Federal e dos Municípios:

${ }^{\mathrm{v}} \mathrm{I}$ - proteger o meio ambiente e combater a poluição em qualquer de suas formas;

${ }^{18}$ Art. 129. São funções institucionais do Ministério Público:

[...]

'II - promover o inquérito civil e a ação civil pública, para a proteção do patrimônio público e social, do meio ambiente e de outros interesses difusos e coletivos;

${ }^{19}$ Art. 170. A ordem econômica, fundada na valorização do trabalho humano e na livre iniciativa, tem por fim assegurar a todos existência digna, conforme os ditames da justiça social, observados os seguintes princípios: ${ }^{\mathrm{v}} \mathrm{I}$ - defesa do meio ambiente, inclusive mediante tratamento diferenciado conforme o impacto ambiental dos produtos e serviços e de seus processos de elaboração e prestação;

${ }^{20}$ SILVA, José Afonso da, op. cit., 2013, p. 49.

${ }^{21}$ FERREIRA, Heline; LEITE, José Rubens Morato. A expressão dos objetivos do Estado de Direito Ambiental na Constituição Federal de 1988. In: LEITE, J.R.M.; FERREIRA, H.S.; CAETANO, M.A. Repensando o Estado Direito Ambiental. Florianópolis: Fundação Boiteux, 2012. p. 43.
} 
de um "Estado de Direito Ambiental", esse modelo de Estado que, nas palavras de José Rubens Morato Leite e Matheus Almeida Caetano ${ }^{22}$, é uma versão "esverdeada e atualizada" dos Estados Liberal e Social, "pois além de proteger os direitos individuais (primeira geração) e sociais (segunda geração), acaba por incorporar os direitos difusos ou de terceira geração, sem quaisquer sobreposições entre as três categorias de direitos fundamentais".

Insiste-se que, para os autores que o defendem, esse novo modelo de Estado não faz tabula rasa das conquistas anteriores alcançadas pelos Estados Liberal e Social, mas, conforme esclarecem Ingo Sarlet e Tiago Fensterseifer ${ }^{23}$, "apenas agrega a elas uma dimensão ecológica, comprometendo-se com a estabilização e prevenção do quadro de riscos e degradação ecológica".

Do tratamento ambiental conferido pela Lei Maior, a norma-raiz ${ }^{24}$ está no art. 225, caput, de seguinte teor:

Art. 225. Todos têm direito ao meio ambiente ecologicamente equilibrado, bem de uso comum do povo e essencial à sadia qualidade de vida, impondo-se ao Poder Público e à coletividade o dever de defendê-lo e preservá-lo para as presentes e futuras gerações.

Do dispositivo transcrito, e para o que importa mais diretamente para o presente estudo, extrai-se que a defesa e a preservação do meio ambiente ecologicamente equilibrado são compartilhadas entre o poder público e a coletividade.

Essa divisão de encargos e responsabilidades, como anota Germana Belchior $^{25}$, está diretamente relacionada ao princípio da solidariedade ${ }^{26}$, o qual, de

${ }^{22}$ LEITE, José Rubens Morato; CAETANO, Matheus Almeida. Breves reflexões sobre os elementos do Estado de Direito Ambiental brasileiro. In: LEITE, J.R.M.; FERREIRA, H.S.; CAETANO, M.A. Repensando o Estado Direito Ambiental. Florianópolis: Fundação Boiteux, 2012. p. 81.

${ }^{23}$ SARLET, Ingo Wolfgan; FENSTERSEIFER, Tiago. Direito Constitucional Ambiental: estudos sobre a Constituição, os Direitos Fundamentais e a proteção do ambiente. São Paulo: Revista dos Tribunais, 2011. p. 42.

${ }^{24} \mathrm{Na}$ dicção de Antônio Herman Benjamin, o caput do art. 225 é a "mãe de todos os direitos ambientais da Constituição brasileira", eis que o dispositivo encerra "a sede de sua organização [do direito ao meio ambiente ecologicamente equilibrado] como direito autônomo e de caráter genérico" (BENJAMIN, Antônio Herman. Constitucionalização do ambiente e ecologização da Constituição brasileira. In: CANOTILHO, J.J.G; LEITE, J.R.M.L. (org). Direito Constitucional Ambiental Brasileiro. 4 ed. São Paulo: Saraiva, 2011. p. 124). Com efeito, o referido dispositivo constitucional estatui o direito (o meio ambiente ecologicamente equilibrado), qualifica-o (bem de uso comum do povo e essencial à sadia qualidade de vida), define seus destinatários (todos, presentes e futuras gerações) e responsáveis (poder público e coletividade), funcionando, por conseguinte, como diretriz estruturante e interpretativa das demais normas constitucionais relacionadas ao meio ambiente.

${ }^{25}$ BELCHIOR, Germana Parente Neiva. Hermenêutica Jurídica Ambiental. São Paulo: Saraiva, 2011.

${ }^{26}$ A concretização do princípio da solidariedade representa o alcance histórico do lema da Revolução Francesa: liberdade, igualdade e fraternidade. Assim, em perspectiva histórica, seguiram-se o Estado Liberal (liberdade), o Estado Social (igualdade) e, mais recentemente, para alguns, o Estado de Direito Ambiental (fraternidade ou solidariedade). 
resto, impregna toda a questão relacionada ao direito ao meio ambiente, como estão a demonstrar a natureza difusa do direito (titularidade de "todos", ultrapassando a esfera individual) e a preocupação com as futuras gerações.

Dissecando a solidariedade presente nesse dever de defesa e proteção compartilhado entre poder público e sociedade, Antônio Herman Benjamin ${ }^{27}$ observa que essa "receita solidarista" diverge da fórmula clássica do "eu-contra-oEstado", típica do Estado Liberal, e também da fórmula "nós-contra-o-Estado", do Welfare State, resultando, na verdade, na nova equação do "nós-todos-em-favordo-planeta". Assim, substitui-se o "eu individualista pelo nós coletivista". E o "nós welfarista" típico, em que os cidadãos demandam do Estado, "passa a agregar, na mesma vala de obrigados, sujeitos públicos e privados, reunidos numa clara, mas constitucionalmente legítima, confusão de posições jurídicas".

Especificamente quanto ao Estado, oportuno identificar alguns significados da norma do art. 225, caput, da Constituição.

Em primeiro lugar, pontua-se que, por "Poder Público", há que se compreender todas as esferas da Federação, é dizer, União, Estados, Distrito Federal e municípios, decorrendo essa leitura diretamente de outras passagens do texto constitucional, mais precisamente do art. 23, VI, que estabelece a competência material comum daqueles entes federativos para "proteger o meio ambiente e combater a poluição em qualquer de suas formas", e do art. 24, VI, que estipula a competência concorrente para legislar sobre "florestas, caça, pesca, fauna, conservação da natureza, defesa do solo e dos recursos naturais, proteção do meio ambiente e controle da poluição".

Consoante anotam Marcia Leuzinger e Sandra Cureau ${ }^{28}$, por "Poder Público" há que se entender, também, os três Poderes do Estado: Executivo, Legislativo e Judiciário, nas suas respectivas esferas de atribuições. Acrescenta-se, contudo, que igualmente há que se ter por "Poder Público", para fins de compreensão do art. 225, caput, da Constituição, os órgãos constitucionais autônomos, a exemplo da Defensoria Pública e do Ministério Público.

Esclareça-se, ademais, que o dever estatal de defesa e proteção do meio ambiente não encerra apenas prestações negativas, é dizer, a abstenção da prática de condutas degradantes ao meio ambiente, mas também prestações positivas, a exemplo da promoção de políticas públicas. A só atuação abstencionista do

${ }^{27}$ BENJAMIN, Antônio Herman, op. cit., 2011. p. 78-79.

${ }^{28}$ LEUZINGER, Marcia Dieguez; CUREAU, Sandra. Direito Ambiental. Rio de Janeiro: Elsevier, 2013. p. 67. 
Estado seria, evidentemente, de todo insuficiente para o cumprimento da missão constitucional atribuída, eis que amiúde, para proteger e defender, é necessária uma postura proativa. Na verdade, no próprio $\S 1^{\circ}$ do art. 225 da Constituição já são previstas atividades que inegavelmente consistem em prestações positivas, a exemplo da restauração dos processos ecológicos essenciais, do manejo ecológico das espécies e ecossistemas (inc. I), da promoção da educação ambiental em todos os níveis de ensino e da conscientização pública para a preservação do meio ambiente (inc. VI).

A propósito do $\S 1^{\circ}$ do art. 225 da Constituição, enumera o dispositivo incumbências a cargo do poder público com o propósito de "assegurar a efetividade" do direito ao meio ambiente ecologicamente equilibrado. Eis o seu teor:

\section{Art. 225. [...]}

$\S 1^{\circ}$ Para assegurar a efetividade desse direito, incumbe ao Poder Público:

I - preservar e restaurar os processos ecológicos essenciais e prover o manejo ecológico das espécies e ecossistemas;

II - preservar a diversidade e a integridade do patrimônio genético do País e fiscalizar as entidades dedicadas à pesquisa e manipulação de material genético;

III - definir, em todas as unidades da Federação, espaços territoriais e seus componentes a serem especialmente protegidos, sendo a alteração e a supressão permitidas somente através de lei, vedada qualquer utilização que comprometa a integridade dos atributos que justifiquem sua proteção;

IV - exigir, na forma da lei, para instalação de obra ou atividade potencialmente causadora de significativa degradação do meio ambiente, estudo prévio de impacto ambiental, a que se dará publicidade; V - controlar a produção, a comercialização e o emprego de técnicas, métodos e substâncias que comportem risco para a vida, a qualidade de vida e o meio ambiente;

VI - promover a educação ambiental em todos os níveis de ensino e a conscientização pública para a preservação do meio ambiente; VII - proteger a fauna e a flora, vedadas, na forma da lei, as práticas que coloquem em risco sua função ecológica, provoquem a extinção de espécies ou submetam os animais a crueldade.

O elenco é meramente exemplificativo. Nas palavras de Ingo Sarlet e Tiago Fensterseifer ${ }^{29}$, o rol está "aberto a outros deveres necessários a uma tutela abrangente e integral do ambiente, especialmente em razão do surgimento

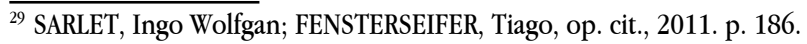


permanente de novos riscos e ameaças à Natureza provocadas pelo avanço da técnica [...]". Efetivamente, não faria qualquer sentido engessar a necessária atuação estatal em prol do meio ambiente nas (importantes, diga-se) tarefas descritas no $\S 1^{\circ}$ do art. 225 da Constituição Federal, eis que os desafios ambientais a serem superados não se esgotam naquele feixe, sendo, ademais, impossível prever os novos riscos que advirão.

A promoção de contratações públicas sustentáveis - uma prestação de natureza eminentemente positiva, a ser realizada por todas as esferas da Federação e por todos os poderes da República e órgãos constitucionais autônomos - é uma tarefa que, inobstante não elencada no rol $\operatorname{do} \$ 1^{\circ}$ do art. 225 , decorre diretamente da Carta Magna. Essa é a tese a ser destrinchada na próxima seção.

\section{AS CONTRATAÇÕES PÚBLICAS SUSTENTÁVEIS COMO IMPOSIÇÃO CONSTI- TUCIONAL}

Preliminarmente, antes de se avançar na pauta proposta para este tópico, justifica-se o emprego da expressão "contratações públicas sustentáveis" em preferência a "licitações públicas sustentáveis", esta que, inegavelmente, obteve maior adoção por parte dos estudiosos que se debruçaram sobre o tema até o momento.

É que aquela primeira expressão parece mais completa para retratar a imposição constitucional de o Estado, quando agir como consumidor, assumir postura sustentável. Sim, porque, como se sabe, há contratações públicas que não são precedidas de licitação, as hipóteses de dispensa e inexigibilidade, e que, a despeito disso, também devem ser sustentáveis.

Ademais, embora o procedimento licitatório em si possa ser "verde", por exemplo, viabilizando-se com redução do consumo de papel ou de energia, a verdade é que, mesmo as disposições do instrumento convocatório que se direcionem à sustentabilidade são destinadas a viabilizar, ao final e ao cabo, uma contratação sustentável, sendo certo que a licitação é apenas um instrumento para se obter um contrato. Logo, estando-se a falar do Estado-consumidor, mais adequada parece a referência ao instrumento que viabiliza o consumo (o contrato) do que ao instrumento que conduz ao contrato (a licitação).

Justificada a opção terminológica, inicia-se por se avaliar que, sendo 
essencial, como visto anteriormente, a utilização racional dos recursos naturais disponíveis diante da crise ambiental vivenciada, e sendo essencial, também, a atuação estatal para que um novo paradigma de crescimento se consolide (o desenvolvimento sustentável), é consectário lógico que o Estado, quando atuar como consumidor, é dizer, quando demandar suas compras, serviços e obras, haverá de pensar na sustentabilidade de seu próprio consumo. No caso do Brasil, sublinhase que o impacto ambiental do consumo estatal está longe de ser desprezível, eis que há estimativas dando conta de que essas despesas representariam 21,5\% do PIB naciona ${ }^{30}$.

Ao lado, porém, da necessidade fática de o consumo estatal ser sustentável, há uma imposição normativa nesse sentido, de matriz constitucional, inclusive.

Deveras, viu-se ser dever constitucional do Estado brasileiro defender e preservar o meio ambiente ecologicamente equilibrado, bem de uso comum do povo e essencial à sadia qualidade de vida, para as presentes e futuras gerações. Ora, para o cumprimento dessa obrigação, é consectário lógico não ser dado ao poder público, ele mesmo, ser vetor de degradação ambiental, raciocínio que impõe seja sua consumação realizada dentro de uma pauta de sustentabilidade. Some-se a isso que, tendo a Carta de 1988 desenhado um Estado sinceramente comprometido com a questão ambiental, seria de todo incongruente pensar que, em aspecto fundamental para seu funcionamento (o seu próprio consumo), pudesse afastar-se daquele compromisso. Seria admitir a possibilidade de um Estado ambientalmente hipócrita.

Contudo, embora a realização de um consumo sustentável, por parte do Estado brasileiro, tenha o condão de, por si só, representar um inegável avanço em termos de proteção, quer parecer que o seu maior efeito em prol do meio ambiente seja o de fomentar a consolidação de um mercado sustentável.

Deveras, dada a fatia do PIB que representam, no Brasil, os gastos públicos com a manutenção material do Estado, resta evidente o potencial do poder de compra estatal como instrumento de política pública para estimulação de qualquer mercado, valendo aqui salientar ser a defesa do meio ambiente princípio da ordem econômica (Constituição Federal, art. 170, VI) a respaldar, portanto, o emprego das

\footnotetext{
${ }^{30}$ ICLEI. Manual Procura + Um Guia para Implementação de Compras Públicas Sustentáveis. 3 ed. São Paulo, 2015. p. 8. Disponível em: < http://sams.test.iclei.org/fileadmin/user_upload/SAMS/Documents/PUBLICACOES/Manual_Procura_BR_final.pdf > . Acesso em: 26 jul. 2015.
} 
contratações públicas sustentáveis enquanto instrumento de regulação do Estado ${ }^{31}$. No particular, cumpre reconhecer que, na realidade, a utilização do poder de compra do Estado, enquanto instrumento de política pública, não configura novidade no ordenamento jurídico pátrio, estando aí como prova o Estatuto Nacional da Microempresa e Empresa de Pequeno Porte que, a título de dar efetividade a dispositivos constitucionais diversos (art. 146, III, $d^{32}$, art. 170, IX $\mathrm{IX}^{33}$ e art. 179 ${ }^{34}$ ), instituiu um tratamento favorecido e diferenciado àquelas entidades na seara das contratações públicas, por meio de instrumentos como preferência de contratação em caso de empate (art. $44^{35}$ ), licitações exclusivas, subcontratação obrigatória e reserva de cota (art. 48, I, II e III $\left.{ }^{36}\right)$.

Contudo, enquanto o tratamento favorecido e diferenciado às micro e

31 Esse raciocínio é compartilhado por Érica Requi, que defende o abandono da concepção de que a contratação pública presta-se, apenas, à satisfação material das necessidades estatais, devendo ser concebida como "instrumento de fomento público, de modo a utilizar o poder de compra do Estado como ferramenta para a regulação da ordem econômica". Esse poder de compra, por conseguinte, deve "promover o desenvolvimento nacional sustentável e implementar políticas ambientais e sociais". (REQUI, Erica Miranda dos Santos. As contratações públicas como instrumento de fomento ao desenvolvimento sustentável. Revista Zênite - Informativo de Licitações e Contratos (ILC). Curitiba: Zênite, n. 218, p. 378-389, abr. 2012.)

${ }^{32}$ Art. 146. Cabe à lei complementar:

[...]

d) definição de tratamento diferenciado e favorecido para as microempresas e para as empresas de pequeno porte, inclusive regimes especiais ou simplificados no caso do imposto previsto no art. 155 , II, das contribuições previstas no art. 195, I e $\S \S 12$ e 13, e da contribuição a que se refere o art. 239.

${ }^{33}$ Art. 170. A ordem econômica, fundada na valorização do trabalho humano e na livre iniciativa, tem por fim assegurar a todos existência digna, conforme os ditames da justiça social, observados os seguintes princípios: I...]

IX-tratamento favorecido para as empresas de pequeno porte constituídas sob as leis brasileiras e que tenham sua sede e administração no País. (Redação dada pela Emenda Constitucional no 6 , de 1995)

${ }^{34}$ Art. 179. A União, os Estados, o Distrito Federal e os Municípios dispensarão às microempresas e às empresas de pequeno porte, assim definidas em lei, tratamento jurídico diferenciado, visando a incentivá-las pela simplificação de suas obrigações administrativas, tributárias, previdenciárias e creditícias, ou pela eliminação ou redução destas por meio de lei.

${ }^{35}$ Art. 44. Nas licitações será assegurada, como critério de desempate, preferência de contratação para as microempresas e empresas de pequeno porte.

${ }^{8} 1^{\circ}$ Entende-se por empate aquelas situações em que as propostas apresentadas pelas microempresas e empresas de pequeno porte sejam iguais ou até $10 \%$ (dez por cento) superiores à proposta mais bem classificada. ${ }^{\S} 2^{\circ} \mathrm{Na}$ modalidade de pregão, o intervalo percentual estabelecido no $\S 10$ deste artigo será de até $5 \%$ (cinco por cento) superior ao melhor preço.

${ }^{36}$ Art. 48. Para o cumprimento do disposto no art. 47 desta Lei Complementar, a administração pública: (Redação dada pela Lei Complementar $n^{\circ} 147$, de 2014)

${ }^{1}$ - deverá realizar processo licitatório destinado exclusivamente à participação de microempresas e empresas de pequeno porte nos itens de contratação cujo valor seja de até $\mathbf{R} \$ 80.000,00$ (oitenta mil reais); (Redação dada pela Lei Complementar $n^{\circ} 147$, de 2014)

II - poderá, em relação aos processos licitatórios destinados à aquisição de obras e serviços, exigir dos licitantes a subcontratação de microempresa ou empresa de pequeno porte; (Redação dada pela Lei Complementar n ${ }^{0}$ 147 , de 2014)

'II - deverá estabelecer, em certames para aquisição de bens de natureza divisível, cota de até $25 \%$ (vinte e cinco por cento) do objeto para a contratação de microempresas e empresas de pequeno porte. (Redação dada pela Lei Complementar n $\mathrm{n}^{\mathrm{T}} 147$, de 2014) 
pequenas empresas em sede de licitações e contratos poderia ou não ter sido adotado, uma vez que a Constituição, em passagem alguma, obriga, especificamente, sequer de modo implícito, a escolha desse caminho (embora seja uma escolha respaldada constitucionalmente, frisa-se ${ }^{37}$ ), a obrigatoriedade de adoção de contratações públicas sustentáveis por parte do poder público é decorrência lógica e necessária do dever estatal instituído no caput do art. 225 da Constituição.

Anota-se que o fato de a questão da sustentabilidade, no âmbito das contratações públicas, ter permanecido adormecida por algum tempo desde a promulgação da Constituição de 1988, tendo sido vista até, em algum momento, como ilegal por afronta ao art. $3^{\circ}, \S 1^{\circ}$, I da lei $n$. $8.666 / 93^{38}$, por supostamente restringir a competividade ${ }^{39}$, não elide a correção do raciocínio de que as contratações públicas sustentáveis são, sim, uma imposição decorrente da própria Constituição.

Sabe-se que a efetivação de uma Carta Constitucional não é um projeto acabado, que se realiza de uma vez só, antes se apresenta como um constante fazer, sendo diversas as normas constitucionais cujas leituras evoluíram com o passar dos anos, a exemplo do que se passou com o mandado de injunçã ${ }^{40}$. Como ponderou Luís Roberto Barroso ${ }^{41}$ por ocasião da feitura de um balanço dos 25 anos da Constituição de 1988, "uma ideia leva um tempo razoável entre o momento em que conquista corações e mentes até torna-se uma realidade concreta". E a ideia da sustentabilidade nas contratações públicas enquanto dever estatal ainda está no processo de conquista.

\footnotetext{
${ }^{37}$ A referência mais explícita ao que consistiria o tratamento diferenciado e favorecido às microempresas e empresas de pequeno porte está no art. 170 da Constituição, que se reporta à "simplificação de suas obrigações administrativas, tributárias, previdenciárias e creditícias, ou pela eliminação ou redução destas por meio de lei". No entanto, nem mesmo nessa passagem se consegue identificar qualquer imposição no sentido de serem as licitações um caminho obrigatório para o cumprimento do dever constitucional de especial tratamento. Numa nota: as licitações apresentavam-se como um caminho possível, mas não obrigatório, de o legislador promover o tratamento diferenciado e favorecido requerido constitucionalmente.

${ }^{38}$ Art. $3^{\circ}[\ldots]$

$\S 1^{\circ}$ É vedado aos agentes públicos:

' - admitir, prever, incluir ou tolerar, nos atos de convocação, cláusulas ou condições que comprometam, restrinjam ou frustrem o seu caráter competitivo, inclusive nos casos de sociedades cooperativas, e estabeleçam preferências ou distinções em razão da naturalidade, da sede ou domicílio dos licitantes ou de qualquer outra circunstância impertinente ou irrelevante para o específico objeto do contrato, ressalvado o disposto nos $\S \S$ 50 a 12 deste artigo e no art. 3 o da Lei no 8.248, de 23 de outubro de 1991;

${ }^{39}$ A informação é trazida por Érica Requi, que historia, ainda, a respeito, que a ideia então defendida era a de que "a inclusão de critérios ambientais, no máximo, poderia ser feita como quesito de pontuação da proposta técnica nas licitações do tipo melhor técnica ou do tipo técnica e preço, com vistas a não frustrar a competitividade". (REQUI, Érica, op.cit.).

${ }^{40}$ Inicialmente visto como meio de dar ciência ao Legislativo da sua mora (MI 107/DF, Rel. Min. Moreira Alves, DJde 21-9-1990), passou o mandado de injunção a ser instrumento judicial de suprir a ausência de norma a fim de assegurar o exercício dos direitos e liberdades que a Constituição buscou preservar (MI 708/DF, Rel. Min. Gilmar Mendes, Plenário, DJE de 31-10-2008).

${ }^{41}$ BARROSO, Luís Roberto. A Constituição Brasileira de 1988: vinte e cinco anos de vida. In: A Constituição de 1988 na visão dos Ministros do Supremo Tribunal Federal. 5 ed. Brasília: Supremo Tribunal Federal, 2015. p. 221.
} 
Antônio Herman Benjamin ${ }^{42}$ pontua que a constitucionalização do ambiente, para além de trazer influências de cunho político e moral, traz consigo benefícios concretos, alguns destes de caráter substantivo, com o condão de reorganizar "a estrutura profunda de direitos e deveres, assim como da própria ordem jurídica".

Dentre esses benefícios substantivos, assinala o autor ${ }^{43}$, está a redução da discricionariedade administrativa, no sentido de não ser conferida ao Estado outra hipótese de comportamento senão aquele de, "na formulação de políticas públicas e em procedimentos decisórios individuais, optar sempre, entre as várias alternativas viáveis ou possíveis, por aquela menos gravosa ao equilíbrio ecológico". Na visão do jurista, o desvio desse dever poderia, inclusive, caracterizar improbidade administrativa e infrações a tipos penais e administrativos. No mesmo viés, estão Ingo Sarlet e Tiago Fensterseifer ${ }^{44}$.

Consolidado que as contratações públicas sustentáveis são uma imposição constitucional, segue daí que a discricionariedade do gestor público resta sensivelmente reduzida, eis que não está mais no seu leque de opções escolher considerar ou não aspectos ambientais em qualquer contratação que venha a realizar; antes deve se esmerar para, no desiderato de alcançar a proposta mais vantajosa para a administração, alcançar o ponto ótimo que congregue preço, qualidade e sustentabilidade.

Essa redução da discricionariedade do gestor público quanto à promoção de contratações públicas sustentáveis, porém, não decorre apenas de uma imposição constitucional, consoante se procurou descortinar na seção que se encerra, mas também de disposições infraconstitucionais nesse sentido, assunto da próxima seção.

\section{AS CONTRATAÇÕES PÚBLICAS SUSTENTÁVEIS COMO IMPOSIÇÃO LEGAL}

Em 2010, a lei n. 12.349 alterou o art. $3^{\circ}$ da lei n. 8.666/93 para inserir "a promoção do desenvolvimento nacional sustentável" como finalidade da licitação:

Art. $3^{\circ}$ A licitação destina-se a garantir a observância do princípio constitucional da isonomia, a seleção da proposta mais vantajosa para a administração e a promoção do desenvolvimento nacional sustentável e será processada e julgada em estrita conformidade

\footnotetext{
$\overline{42}$ BENJAMIN, Antônio Herman, op. cit., 2011. p. 89.

${ }^{43}$ Ibidem, 2011. p. 95.

${ }^{44}$ SARLET, Ingo Wolfgan; FENSTERSEIFER, Tiago, op. cit., 2011. p. 184.
} 
com os princípios básicos da legalidade, da impessoalidade, da moralidade, da igualdade, da publicidade, da probidade administrativa, da vinculação ao instrumento convocatório, do julgamento objetivo e dos que lhes são correlatos. (Grifo nosso)

Essa alteração legislativa foi percebida, por alguns, como o marco legal que transformou a discricionariedade do gestor em promover a sustentabilidade nas compras públicas em obrigatoriedade ${ }^{45} \mathrm{e}$, por outros, como o ato legislativo autorizador somente a partir do qual foi possível realizar compras públicas sustentáveis $^{46}$.

Com o devido acatamento, consoante se acredita ter evidenciado alhures, a promoção de contratações sustentáveis é imposição, e não faculdade, decorrente da Constituição Federal.

Sem se querer retomar todos os argumentos já externados, insiste-se, apenas, no raciocínio lógico segundo o qual o poder público, por força do seu dever constitucional de proteger e preservar o meio ambiente ecologicamente equilibrado, não pode, quando atuar como consumidor, comportar-se de modo ambientalmente descompromissado. Mais específicamente: não tem a discricionariedade de optar por degradar ou não degradar o meio ambiente, ou não levar em conta, no seu planejamento de gastos, a pauta ambiental, assim como não lhe é dado deixar de observar outros princípios que igualmente estão incrustados à sua estrutura, a exemplo da legalidade, da moralidade, da publicidade, da economicidade, dentre tantos outros.

Registra-se que esse assentamento constitucional das contratações públicas sustentáveis é essencial não só pela relevância que, inegavelmente, assume um dever estatal quando enraizado diretamente na Constituição, mas também porque, no campo prático, há desdobramentos não desprezíveis.

Assim, por exemplo, se é apenas a Lei (e não a Constituição) o fundamento e o limite das contratações públicas sustentáveis, haver-se-ia que admitir que, tendo a lei previsto o desenvolvimento nacional sustentável como finalidade da licitação (é isso que está escrito no art. $3^{\circ}$ da lei n. 8.666/93), e não do contrato,

\footnotetext{
$\overline{45}$ Nesse sentido, Teresa Barki, ressaltando a autora que a discricionariedade de que dispunha o gestor antes da inovação legislativa estava respaldada na Constituição (BARKI, Teresa Villac Pinheiro. Licitação e desenvolvimento nacional sustentável. Debates em Direito Público, Belo Horizonte, ano 10, n. 10, out. 2011).

${ }^{46}$ Nesse sentido, Marçal Justen Filho. Para o autor, a realização de outras finalidades pela licitação apresenta um custo econômico e, assim, uma solução economicamente menos vantajosa somente poderia ser feita mediante aprovação dos cidadãos, ou seja, mediante lei aprovada por seus representantes. Então conclui que "essa é a relevância da alteração da redação do art. $3^{\circ}$ por parte da Lei 12.349/2010, eis que foi assegurada a autorização legislativa para a elevação de despesas com contratações públicas utilizadas para a promoção de outras finalidades." (JUSTEN FILHO, Marçal. Comentários à Lei de Licitações e Contratos Administrativos. 16ed. São Paulo: Revista dos Tribunais, 2014. p. 78).
} 
hipóteses de dispensa e inexigibilidade não estariam comprometidas com a ideia de sustentabilidade e, por conseguinte, estaria livre o administrador para simplesmente ignorar o assunto nesses casos. Haver-se-ia que admitir, ainda, que, se o legislador ordinário, por alguma contingência histórica ${ }^{47}$, decidisse retirar o desenvolvimento sustentável das finalidades atribuídas à licitação, então promover licitações sustentáveis voltaria a ser discricionário ou até proibido.

Acredita-se que, na verdade, a nova redação do art. $3^{\circ}$ da lei n. 8.666/93 teve o mérito de tornar explícita, em diploma que possui o status de norma geral em tema de licitações e contratos administrativos, uma vontade constitucional que, até então, de modo geral, passava despercebida. A inovação legislativa, ao tempo em que iluminou a questão, sendo prova disso os diversos trabalhos doutrinários que se seguiram, desencadeou um importante processo de concretização da norma constitucional, eis que, depois dela, a proteção ambiental tem-se imposto, com força crescente, na pauta dos gestores públicos, embora ainda haja um longo caminho a ser percorrido, em face das dificuldades práticas que o tema atrai ${ }^{48}$.

Salienta-se, a título de registro, que no plano infraconstitucional, afora o art. $3^{\circ}$ da lei n. 8.666/93, há ainda outros diplomas que versam sobre o tema da sustentabilidade nas licitações e contratações públicas, alguns até anteriores à lei n. 12.349/2010, os quais, em graus e searas diversos, vinculam o gestor público e o orientam nesse desafio que é transpor para a realidade a promoção do desenvolvimento sustentável por meio do consumo estatal. Sem qualquer pretensão de esgotamento do elenco existente, eis que o intuito é, apenas, ilustrar o arcabouço infraconstitucional existente, cita-se, nesse sentido, a Política Nacional sobre Mudança do Clima (art. $6^{\circ}$, inc. XII, lei n.12.187/2009) ${ }^{49}$, a Lei Nacional de Resíduos

\footnotetext{
47 A hipótese não é mero exercício de retórica. Recuo legislativo em matéria ambiental tem precedente. Nesse sentido, mencionam-se os retrocessos trazidos pelo Novo Código Florestal (Lei n. 12.651/2012) apontados por Márcia Leuzinger e Sandra Cureau (LEUZINGER, Marcia Dieguez; CUREAU, Sandra, op. cit., 2013, p. 163-190).

${ }^{48}$ Pode-se gastar mais para realizar contratações sustentáveis? Em caso positivo, qual o limite? Quais os aspectos que definem um objeto ambientalmente correto? Se é certo que a descrição do objeto pode conter detalhes que orientem à sustentabilidade, surge, porém, uma dúvida quanto aos requisitos de habilitação: pode-se restringir a disputa apenas àquelas licitantes ambientalmente sustentáveis? Essas e outras dúvidas não são de fácil enfrentamento, encontram repostas as mais variadas na doutrina e, como se disse na introdução deste artigo, reclamam estudo específico.

${ }^{49}$ Art. $6^{\circ}$ São instrumentos da Política Nacional sobre Mudança do Clima:

I...]

XII - as medidas existentes, ou a serem criadas, que estimulem o desenvolvimento de processos e tecnologias, que contribuam para a redução de emissões e remoções de gases de efeito estufa, bem como para a adaptação, dentre as quais o estabelecimento de critérios de preferência nas licitações e concorrências públicas, compreendidas aí as parcerias público-privadas e a autorização, permissão, outorga e concessão para exploração de serviços públicos e recursos naturais, para as propostas que propiciem maior economia de energia, água e outros recursos naturais e redução da emissão de gases de efeito estufa e de resíduos;
} 
Sólidos (art. 70, inc. XI, “a" e "b", da lei n. 12.305/2010) ${ }^{50}$, o Regime Diferenciado de Contrações (art. $3^{\mathrm{o}}$ e art. $4^{\mathrm{o}}$, III e $\left.\S 1^{\mathrm{o}}\right)^{51}$ e, no plano federal, a Instrução Normativa SLTI/MPOG $\mathrm{n}^{0} 1$, de 19 de janeiro de $2010^{52}$.

Mas, voltando-se ao artigo $3^{\circ}$ e à "nova" finalidade da licitação pública (a promoção do desenvolvimento nacional sustentável), o que se deve perceber é que não se pode mais compreender por proposta mais vantajosa, apenas, aquela que apresente o menor preço. Efetivamente, essa ideia equivocada, por algum motivo, cristalizou-se ao longo da vigência da lei n. 8.666/93, contribuindo para a realização de compras de baixíssima qualidade, o que, ao final e ao cabo, trouxe prejuízos inclusive econômicos ao erário. Tudo porque se equiparou um critério de julgamento (o menor preço) com o conceito de proposta mais vantajosa e, assim, entendeu-se que somente se podia pagar pelo que fosse mais barato, independentemente da qualidade do objeto ${ }^{53}$.

Com efeito, na atualidade, em face das demandas contemporâneas que reclamam um novo perfil de Estado, e considerando-se que a Constituição, quando se reporta à Administração Pública, determina que atue pautada em eficiência (art. 37, caput) e sustentabilidade (por todos, cita-se o art. 225, caput), somente se pode

\footnotetext{
${ }^{50}$ Art. $7^{\circ}$ São objetivos da Política Nacional de Resíduos Sólidos:

[...]

XI - prioridade, nas aquisições e contratações governamentais, para:

a) produtos reciclados e recicláveis;

b) bens, serviços e obras que considerem critérios compatíveis com padrões de consumo social e ambientalmente sustentáveis;

${ }^{51}$ Art. $3^{\circ}$ As licitações e contratações realizadas em conformidade com o RDC deverão observar os princípios da legalidade, da impessoalidade, da moralidade, da igualdade, da publicidade, da eficiência, da probidade administrativa, da economicidade, do desenvolvimento nacional sustentável, da vinculação ao instrumento convocatório e do julgamento objetivo.

${ }^{\mathrm{A}} \mathrm{rt} .4^{\mathrm{O}}$ Nas licitações e contratos de que trata esta Lei serão observadas as seguintes diretrizes:

[...]

III - busca da maior vantagem para a administração pública, considerando custos e benefícios, diretos e indiretos, de natureza econômica, social ou ambiental, inclusive os relativos à manutenção, ao desfazimento de bens e resíduos, ao índice de depreciação econômica e a outros fatores de igual relevância;

$\S 1$ As contratações realizadas com base no RDC devem respeitar, especialmente, as normas relativas à:

${ }^{\mathrm{I}}$ - disposição final ambientalmente adequada dos resíduos sólidos gerados pelas obras contratadas;

II - mitigação por condicionantes e compensação ambiental, que serão definidas no procedimento de licenciamento ambiental;

III - utilização de produtos, equipamentos e serviços que, comprovadamente, reduzam o consumo de energia e recursos naturais;

IV - avaliação de impactos de vizinhança, na forma da legislação urbanística;

${ }^{v}$ - proteção do patrimônio cultural, histórico, arqueológico e imaterial, inclusive por meio da avaliação do impacto direto ou indireto causado pelas obras contratadas; e

${ }^{V_{I}}$ - acessibilidade para o uso por pessoas com deficiência ou com mobilidade reduzida.

${ }^{52}$ Dispõe sobre os critérios de sustentabilidade ambiental na aquisição de bens, contratação de serviços ou obras pela Administração Pública Federal direta, autárquica e fundacional e dá outras providências.

${ }^{53}$ Detalhando melhor o raciocínio, no equivocado entendimento que se cristalizou, se somente se podia pagar pelo que fosse mais barato, qualquer descrição do objeto que prestigiasse, também, a qualidade, era rechaçada e, por conseguinte, também qualquer maior exigência de qualificação técnica e econômica.
} 
considerar, dentro de uma contratação pública, como mais vantajosa, uma proposta que congregue, no nível ótimo possível, preço, qualidade e sustentabilidade. Qualquer leitura que aparte uma dessas facetas como elemento indispensável de uma proposta vantajosa não encontra guarida no ordenamento jurídico e, ademais, desconecta-se do direito fundamental do cidadão à boa administração ${ }^{54}$.

\section{CONSIDERAÇÕES FINAIS}

Deixa-se, então, assentada neste trabalho, a tese de que, além de contingências históricas que impelem que o Estado faça e fomente o consumo sustentável, no Brasil, a realização de contratações públicas sustentáveis decorre de mandamento constitucional e legal, não sendo, por conseguinte, facultado ao gestor público, a quem se opõe o direito fundamental à boa administração, não planejar as compras públicas, nelas inserindo a temática da sustentabilidade.

A consolidação da ideia de contratações públicas sustentáveis enquanto dever estatal parece fundamental quando se constata que, em boa parte das administrações públicas do país, o assunto ainda é, simplesmente, ignorado, em postura que desafia o ordenamento jurídico vigente. Também desafiador nesse sentido é o decreto federal n. 7.746/2012 que, a título de regulamentar o art. $3^{\circ} \mathrm{da}$ lei no 8.666/93 "para estabelecer critérios, práticas e diretrizes para a promoção do desenvolvimento nacional sustentável nas contratações realizadas pela administração pública federal", considerou as contratações públicas sustentáveis como opção discricionária do gestor $\left(\operatorname{art.} 2^{\circ}\right)^{55}$, afastando-se, por conseguinte, da Constituição e da lei, que as têm como obrigatórias.

\footnotetext{
${ }_{54}$ Em artigo vanguardista, Juarez Freitas defende a reformulação completa do direito administrativo brasileiro a partir da incidência direta e imediata do "direito fundamental à boa administração" que, nas suas palavras, "é o direito fundamental à administração pública eficiente e eficaz, proporcional cumpridora de seus deveres, com transparência, motivação, imparcialidade e respeito à moralidade, à participação social e à plena responsabilidade por suas condutas omissivas e comissivas". Essencialmente, o direito à boa administração requer um gestor que, ao tempo em que observe o iter exigido de um Estado democrático de Direito, esmere-se no atingimento dos valores consagrados na Constituição Federal. Acertadamente, o autor proclama que o direito à boa administração é incompatível com a "discricionariedade desmesurada" e a "inércia paralisante", dois males da prática administrativa brasileira. (FREITAS, Juarez. Direito administrativo e gestão sustentável. Revista Zênite - Informativo de Licitações e Contratos (ILC), Curitiba: Zênite, n. 229, p. 270-276, mar. 2013).

55 Art. $2^{\circ} \mathrm{A}$ administração pública federal direta, autárquica e fundacional e as empresas estatais dependentes poderão adquirir bens e contratar serviços e obras considerando critérios e práticas de sustentabilidade objetivamente definidos no instrumento convocatório, conforme o disposto neste Decreto.

Parágrafo Único. A adoção de critérios e práticas de sustentabilidade deverá ser justificada nos autos e preservar o caráter competitivo do certame.
} 
É preciso que se perceba que a noção de proposta mais vantajosa está irremediavelmente ressignificada, ao menos no plano normativo, e que não há mais espaço para que, dentro de um planejamento estatal de contratação, não se visualize aquele objetivo como um amálgama indissolúvel de preço, qualidade e sustentabilidade. Na verdade, assim como hoje não se fala em contratações públicas "isonômicas" ou "morais" (porque subtendido que todas o são ou deveriam ser), antevê-se o dia em que o termo "contratações públicas sustentáveis" não passará de um pleonasmo desnecessário.

\section{REFERÊNCIAS}

BARROSO, Luís Roberto. A Constituição Brasileira de 1988: vinte e cinco anos de vida. In: A CONSTITUIÇÃO de 1988 na visão dos Ministros do Supremo Tribunal Federal. 5 ed. Brasília: Supremo Tribunal Federal, 2015.

BARKI, Teresa Villac Pinheiro. Licitação e desenvolvimento nacional sustentável. Debates em Direito Público, Belo Horizonte, v. 10, n. 10, out. 2011.

BELCHIOR, Germana Parente Neiva. Hermenêutica Jurídica Ambiental. São Paulo: Saraiva, 2011.

BENJAMIN, Antônio Herman. Constitucionalização do ambiente e ecologização da Constituição brasileira. In: CANOTILHO, J.J.G; LEITE, J.R.M.L. (Org.). Direito Constitucional Ambiental Brasileiro. 4. ed. São Paulo: Saraiva, 2011.

BUARQUE, Sérgio. Construindo o desenvolvimento local sustentável: metodologia de planejamento. 4. ed. Rio de Janeiro: Garamond, 2008.

BOULDING, Kenneth. The economics of the coming spaceship Earth, 1966. Disponível em: <http://www.ub.edu/prometheus21/articulos/obsprometheus/ BOULDING.pdf $>$. Acesso em: 25 jul. 2015.

BRUNDTLAND, Gro (Rel.). Nosso futuro comum: Comissão Mundial sobre Meio Ambiente e Desenvolvimento. 2. ed. Rio de Janeiro: Fundação Getúlio Vargas, 1991.

DIAMOND, Jared. Colapso: como as sociedades escolhem os fracassos ou o sucesso.

5. ed. Rio de Janeiro: Record, 2007. 
DINO, Nicolao. Proteção jurídica do meio ambiente. Belo Horizonte: Del Rey, 2003.

FERREIRA, Heline; LEITE, José Rubens Morato. A expressão dos objetivos do Estado de Direito Ambiental na Constituição Federal de 1988. In: LEITE, J.R.M.; FERREIRA, H.S.; CAETANO, M.A. Repensando o Estado Direito Ambiental. Florianópolis: Fundação Boiteux, 2012.

FREITAS, Juarez. Direito administrativo e gestão sustentável. Revista Zênite Informativo de Licitações e Contratos (ILC), Curitiba, n. 229, p. 270-276, mar. 2013.

ICLEI. Manual Procura+: Um Guia para Implementação de Compras Públicas Sustentáveis. 3 ed. São Paulo, 2015. p. 8. Disponível em: < http://sams.test.iclei. org/fileadmin/user_upload/SAMS/Documents/PUBLICACOES/Manual_Procura_BR_ final.pdf $>$. Acesso em: 26 jul. 2015.

JUSTEN FILHO, Marçal. Comentários à Lei de Licitações e Contratos Administrativos. 16. ed. São Paulo: Revista dos Tribunais, 2014.

LEITE, José Rubens Morato; CAETANO, Matheus Almeida. Breves reflexões sobre os elementos do Estado de Direito Ambiental brasileiro. In: LEITE, J.R.M.; FERREIRA, H.S.; CAETANO, M.A. Repensando o Estado Direito Ambiental. Florianópolis: Fundação Boiteux, 2012.

LEUZINGER, Marcia Dieguez; CUREAU, Sandra. Direito Ambiental. Rio de Janeiro: Elsevier, 2013.

MEADOWS, Donella et. al. Limites do crescimento: um relatório para o Projeto do Clube de Roma sobre o Dilema da Humanidade. 2. ed. São Paulo: Perspectiva, 1978.

REQUI, Érica Miranda dos Santos. As contratações públicas como instrumento de fomento ao desenvolvimento sustentável. Revista Zênite - Informativo de Licitações e Contratos (ILC), Curitiba, n. 218, p. 378-389, abr. 2012.

SARLET, Ingo Wolfgan; FENSTERSEIFER, Tiago. Direito Constitucional Ambiental: estudos sobre a Constituição, os Direitos Fundamentais e a proteção do ambiente. São Paulo: Revista dos Tribunais, 2011. 
SILVA, José Afonso da. Direito Ambiental Constitucional. 10. ed. São Paulo: Malheiros, 2013.

Recebido em: 05 de novembro de 2015 Aceito em: 12 de janeiro de 2016 